\title{
Erratum to: Recent Developments in the Social Scientific Study of Canadian Jews
}

\author{
David S. Koffman • Morton Weinfeld
}

Published online: 18 September 2011

(C) Springer Science + Business Media B.V. 2011

\section{Erratum to: Cont Jewry \\ DOI 10.1007/s12397-011-9066-7}

Unfortunately, the author name has been misspelled as Morton Weinefeld instead of Morton Weinfeld.

The correct version of author group appears in this erratum.

The online version of the original article can be found under doi:10.1007/s12397-011-9066-7.

\section{S. Koffman ( $ه)$}

New York University, New York City, USA

e-mail: davidkoffman@yahoo.com

M. Weinfeld

McGill University, Montreal, QC, Canada 